\title{
Produto Educacional: potencializando a produção de significados de alunos do ensino fundamental por meio de tarefas de educação financeira realizadas via chat
}

Educational Product: empowering the production of meanings of elementary school students through financial education tasks carried out via chat

\author{
Meiriele Nonato de Oliveira Saiol ${ }^{1}$ \\ Leonardo José da Silva²
}

\begin{abstract}
Resumo
O presente artigo apresenta o produto educacional gerado a partir de uma pesquisa desenvolvida durante o mestrado profissional. O produto é composto por um conjunto de tarefas ligadas a formação de sujeitos críticos nas tomadas de decisões financeiroeconômicas e por um tutorial para professores de matemática trabalhar essas tarefas com alunos do 9 ํ ano do ensino fundamental por meio de chat da internet. As tarefas elaboradas foram baseadas no Modelo dos Campos Semânticos, a fim de estimularem a produção de significados dos estudantes e focadas na educação financeira destes e no desenvolvimento delas por meio do bate-papo. Já o tutorial foi elaborado com base na experiência da professora-pesquisadora mediante a pesquisa visando o auxílio dos profissionais da educação que desejam trabalhar essas tarefas com os alunos por meio de aulas chats de matemática.
\end{abstract}

Palavras-chave: Educação Matemática. Educação Financeira. Produto educacional. Produção de significados. Chat.

\section{Abstract}

The present article presents the educational product generated from a research developed during the professional master 's degree. The product is composed of a set of tasks linked to the formation of critical subjects in financial-economic decision-making and a tutorial for mathematics teachers to work these tasks with students of the 9th grade through internet chat. The tasks elaborated were based on the Semantic Fields Model, in order to stimulate the production of meanings of the students and focused on their financial education and their development through the chat. Already the tutorial was

\footnotetext{
${ }^{1}$ Mestre em Educação Matemática (UFJF), professora da rede estadual de ensino de Minas Gerais, meirinonato@yahoo.com.br

${ }^{2}$ Doutor em Educação para a Ciência (UNESP), professor do departamento de Matemática do Colégio de Aplicação João XXIII da Universidade Federal de Juiz de Fora (UFJF), professor do Programa de PósGraduação em Educação Matemática - ICE/UFJF, leonardo.silva@ufjf.edu.br
} 
elaborated based on the experience of the teacher-researcher through the research aiming the aid of the professionals of the education who wish to work these tasks with the students through classes chats of mathematics.

Keywords: Mathematics Education. Financial education. Educational product. Production of meanings. Chat.

\section{Introdução}

O produto educacional apresentado é parte integrante de nossa pesquisa de mestrado ${ }^{3}$ que investigou a produção de significados de estudantes do ensino fundamental para tarefas financeiro-econômicas e analisou as interações ocorridas durante o desenvolvimento das tarefas por meio de aulas chats. A pesquisa foi feita com alunos de uma turma 9o ano, na qual lecionava a professora-pesquisadora.

A pesquisa desenvolvida é fruto de nossos anseios mediante a sociedade contemporânea em que vivemos. De um lado uma sociedade formada por indivíduos-consumidores (KISTEMANN JR., 2011), líquido-moderna, "inóspito ao planejamento, investimento e armazenamento de longo prazo." (BAUMAN, 2008, p.45). É nela que vemos nossos alunos como reféns diante de tomadas de decisões financeiro-econômicas, sem nenhuma formação voltada para a educação financeira. De outro lado, uma sociedade imersa nas novas tecnologias, no entanto pouco se vê no campo educacional a utilização das inúmeras ferramentas e possibilidades que a tecnologia nos oferece.

Visando essas duas faces da nossa sociedade e buscando romper com as aulas tradicionais que concentram a fala na pessoa do professor é que propomos um trabalho interessado em colaborar com a produção de significados dos alunos para tarefas voltadas para o processo de educação financeira destes e simultaneamente utilizar o chat, um recurso tecnológico que possibilite isso.

\footnotetext{
${ }^{3}$ Pesquisa desenvolvida no Programa de Mestrado Profissional em Educação Matemática da Universidade Federal de Juiz de Fora, apresentada na dissertação intitulada "Chat e Educação Financeira escolar: investigando interações em um ambiente virtual de aprendizagem”.
} 
Para a análise dos significados produzidos pelos alunos e das interações ocorridas no chat foram criadas categorias das mensagens baseadas nos trabalhos de Silva (2013) e Flanders (1970, apud GONZÁLIS E LÉON, 2009).

A pesquisa desenvolvida no mestrado originou o produto educacional composto por um conjunto de tarefas criado com base no Modelo dos Campos Semânticos a fim de estimular a produção de significados dos estudantes, além disso, busca o processo de educação financeira dos mesmos e interação com as novas tecnologias. As tarefas foram elaboradas para serem trabalhadas por meio do chat da internet e com um número reduzido de participantes. Para isso, o mesmo produto contém um tutorial com todas as direções necessárias para o professor de matemática trabalhar tais tarefas com seus alunos.

No decorrer do texto o leitor terá acesso a detalhes de nosso trabalho.

\section{Produto Educacional}

O ensino da matemática é um processo que pode ser auxiliado por diversas técnicas, materiais pedagógicos e metodologias. Os produtos educacionais vêm sendo criados e disponibilizados com esse enfoque. Em particular o produto considerado neste trabalho objetiva ajudar professores de matemática a desenvolverem aulas voltadas para o processo de educação financeira dos alunos e a uma maior participação dos mesmos mediante o desenvolvimento de tarefas em aulas chats.

O produto educacional está organizado em duas partes. A primeira constitui-se em um tutorial direcionado a professores de matemática, pensado e editado a partir da pesquisa realizada com alunos do $9^{\circ}$ ano do ensino fundamental de uma escola pública de Juiz de Fora. A segunda parte é formada pelo conjunto de tarefas desenvolvidas especialmente para serem feitas nesse ambiente virtual. 


\subsection{Tutorial}

A pesquisa realizada durante o mestrado profissional proporcionou uma experiência inédita para a professora-pesquisadora com aulas chats. Essa vivência deu frutos e o tutorial é um deles. Com base nas análises das interações ocorridas durante as aulas no ambiente virtual foi possível elaborar uma espécie de passo-a-passo para os professores que aspiram trabalhar com seus alunos as tarefas também desenvolvidas durante a pós-graduação da pesquisadora.

O tutorial traz vários direcionamentos como os recursos necessários para realização das aulas chats, a sugestão do bate-papo Hangouts, a divisão da turma de alunos em grupos menores no chat e até mesmo uma estimativa do tempo necessário para o fechamento de cada tarefa. A seguir podemos visualizar como é apresentado o tutorial no produto educacional.

Figura 1. Fragmento do tutorial.

\section{TUTORIAL}

- Recursos: Computador / Smartphone, internet Wifi/Dados móveis.

- Sugestão do bate papo: Hangouts

Escolhemos o Hangouts, bate-papo disponibilizado para quem tem uma conta de e-mail Google.

- Criação do endereço de E-mail: Gmail - Google

Fonte: Elaborado pelos autores.

Conforme descrito no tutorial, para a realização das aulas chats, o professor e os alunos devem dispor de um computador ou smartphone conectado a internet, seja por meio de dados móveis ou Wifi. Além disso, todos os participantes devem ter tempo extraescolar disponível para as aulas que duram em média uma hora e meia.

As aulas online deverão ocorrer por meio de um bate-papo. Sugerimos o Hangouts que é chat da Google, vem instalado na maioria dos smartphones, é 
gratuito e de fácil utilização. Além de trocas de mensagens, esse aplicativo permite formação de grupos com até 150 pessoas, compartilhamento de fotos, vídeos, mapas, emoticons. Para acesso ao Hangouts é necessário criar uma conta Google.

O tutorial ainda apresenta o passo-a-passo da criação dessa conta e conta com imagens ilustrativas para auxiliar o professor, como vemos na figura a seguir a fim de mostrar a página de criação da conta Google.

Figura 2. Página de criação da conta Google



Fonte: Google

As diferenças encontradas entre 0 acesso do deste bate-papo por computador ou por um smartphones também são mostradas no tutorial, como vemos respectivamente, nas figuras seguintes. 
http://dx.doi.org/10.5965/2357724X06112018282

Figura 3. Hangouts tela do computador



Fonte: Gmail

Figure 4. Hangouts no smartphone

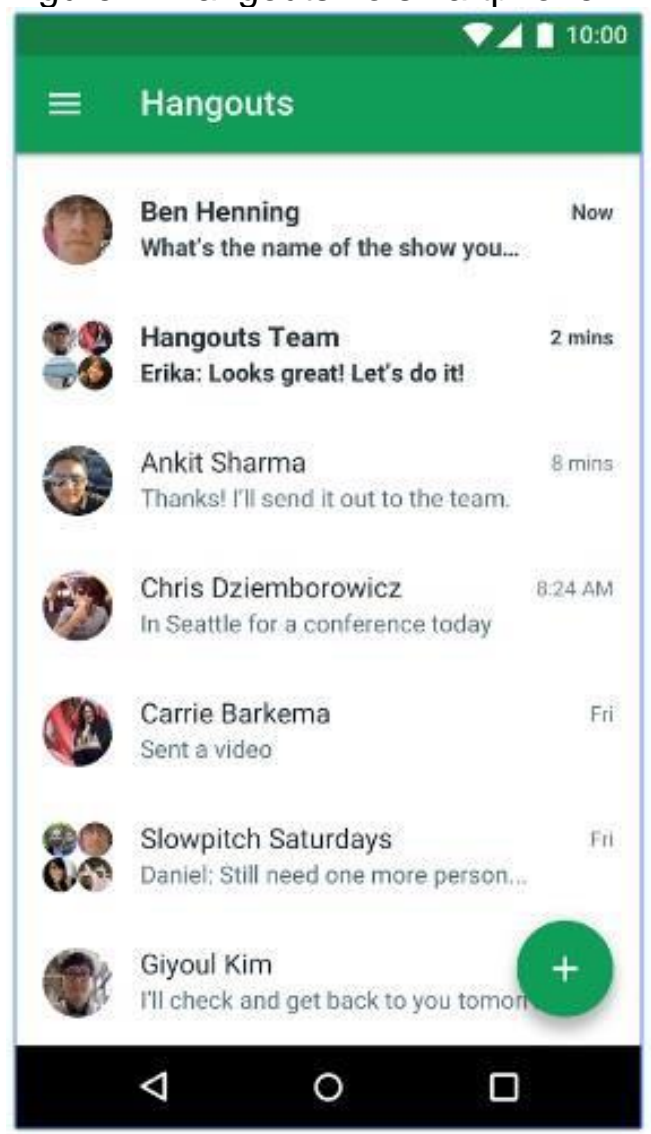

Fonte: Google 
Inicialmente, o professor deverá criar um grupo único com todos os alunos que enviaram e-mail. Esse será um meio para instruções gerais para todos os participantes. $O$ grupo único deverá ser dividido em subgrupos de 5 a 7 alunos, de preferência por escolha dos próprios estudantes. O professor fará parte de todos os subgrupos.

Cada aula chat deverá durar aproximadamente uma hora e meia, podendo estender ou encerrar de acordo com a demanda e disponibilidade do grupo. Lembrando sempre que aulas muito longas podem cansar os estudantes e comprometer o bom rendimento.

\subsection{Tarefas}

O segundo componente do produto educacional é o conjunto de quatro tarefas. As tarefas foram elaboradas com base no Modelo dos Campos Semânticos (MCS) do educador matemático Lins (1999). O modelo foi utilizado decorrente de um dos objetivos da pesquisa ser centralizado nas produções de significados dos estudantes no interior das tarefas. Vale ressaltar que significado, de acordo com o MCS pode ser considerado como sendo aquilo que o sujeito pode e efetivamente diz sobre um objeto no interior de uma atividade.

Todas as tarefas trazem detalhamentos do contexto a que está inserida, do objetivo geral, os conteúdos matemáticos necessários para realização e o tempo médio de duração de cada aula, conforme podemos ver na imagem a seguir.

Figura 5. Fragmento da tarefa 2

- Contexto: A tarefa proposta traz um vídeo sobre a importância da água.

- Objetivo: A formação de sujeitos críticos frente a economia hídrica e financeira.

- Conteúdos Matemáticos: Operações básicas (adição, subtração).

- Duração média de aula: 1 hora e 30 minutos

Fonte: Elaborado pelos autores.

A finalidade de analisar as produções de significados dos alunos mediante as tarefas nos fez iniciá-las com texto, vídeo ou link de reportagem da internet, 
ambos disparadores do processo comunicativo, isto é, que motivam as interações entre os sujeitos participantes. Assim, todas as tarefas do produto educacional começam com a chamada para o "Contextualizando", conforme podemos visualizar a seguir em uma das tarefas.

Figura 6. Fragmento da tarefa 2

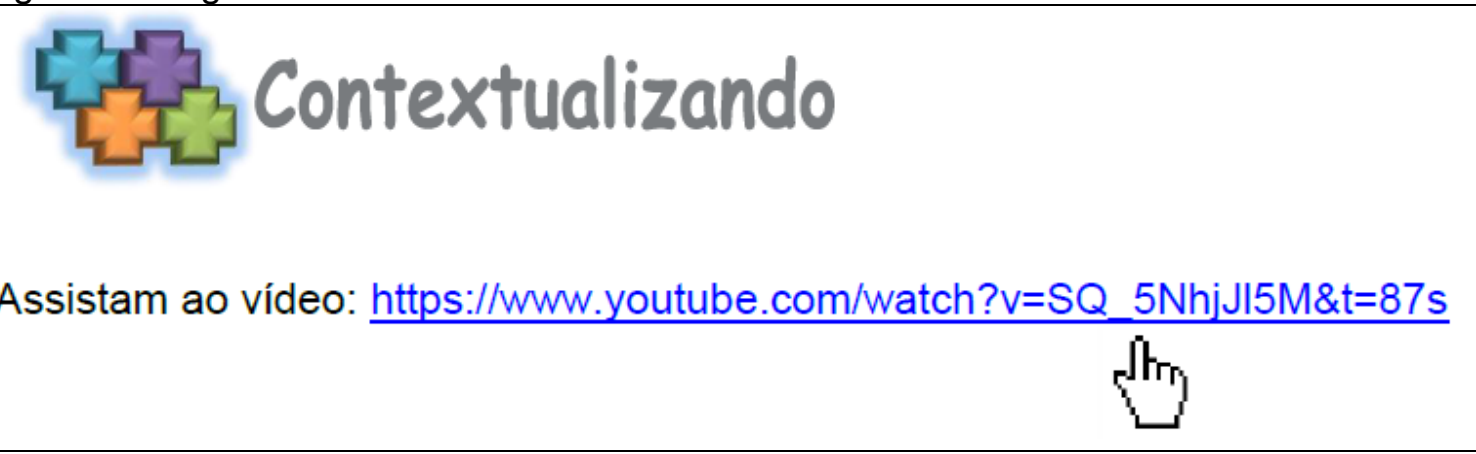

Fonte: Elaborado pelos autores.

Após a introdução de cada tarefa através do "Contextualizando", os alunos tem suas mensagens direcionadas por meio de perguntas. Isso facilita a organização das ideias do grupo. As perguntas devem ser lançadas uma a uma pelo professor mediador das interações, ou seja, após a percepção do educador que uma pergunta foi respondida por todos os participantes, independente de chegarem à única resposta ou não. Ressaltamos que nossas tarefas não possuem resposta única, pois acreditamos que as situações que dependem de tomada de decisões financeiro-econômicas são rodeadas de inúmeros fatores que devem ser levados em consideração e são variáveis. A seguir vemos um fragmento de uma das tarefas contendo alguns questionamentos. 
Figura 7. Fragmento da tarefa 2

Agora é Com Vocês
1) Quais utilidades tem a água em nosso dia-a-dia?
2) Utilizem a calculadora do gasto de consumo de água disponibilizada no link a
seguir e calculem o gasto diário de água (em litros) necessário para uma
http:/lespeciais.g1.globo.com/economia/crise-da-agua/calculadora-do-consumo/
3) Qual o maior vilão do consumo de água no cotidiano de uma pessoa?
4) Segundo a Organização das Nações Unidas (ONU) a quantidade diária de água
necessária para uma pessoa é 110 litros. Vocês acham que é possível viver
com esse consumo de água diário individual? Por quê?

Fonte: Elaborado pelos autores.

Todas as tarefas do produto educacional vêm acompanhadas de um detalhamento de cada questão que será proposta aos estudantes a fim de auxiliar o professor de matemática, conforme vemos a seguir o detalhamento de parte de uma das tarefas. 
Figura 8. Fragmento do detalhamento das questões da tarefa 2

A introdução da tarefa, Contextualizando, busca através do vídeo ser um disparador de interações dos alunos no chat.

A Primeira Questão objetiva levar os alunos a refletirem sobre as diversas formas de consumo de água e sua vital importância para nós.

A Segunda Questão disponibiliza uma calculadora do gasto de consumo de água através da qual os alunos devem calcular o consumo diário de água de uma pessoa, de acordo com o entendimento e experiência deles.

Já a Terceira Questão visa levar os estudantes a observarem o maior vilão de gasto com água nas tarefas diárias de uma pessoa.

A questão seguinte, a Quarta Questão, traz como informativo a quantidade de água necessária para uma pessoa e interroga os alunos se o consumo de água sugerido pela ONU é suficiente.

Fonte: Elaborado pelos autores.

Com exceção da Tarefa 1, que foi a primeira elaborada e a única utilizada durante as interações entre os sujeitos de pesquisa nas aulas chats via Hangouts, as outras três foram criadas a fim de gerar um maior aproveitamento dos recursos tecnológicos oferecidos pelo uso do computador e internet. A exploração desses recursos nas últimas tarefas elaboradas só foi possível devido à percepção da professora-pesquisadora durante as análises da pesquisa.

\section{Considerações}

O Mestrado Profissional visa a formação continuada de profissionais das mais diversas áreas do conhecimento e, em particular da Educação Matemática. Essa modalidade de pós-graduação propicia a criação e apresentação de propostas de novas metodologias de ensino que visem impactar e auxiliar a aprendizagem matemática através do produto educacional.

Nossa proposta de ensino apresenta metodologias que assessoram professores de matemática na articulação do trabalho da Educação Financeira, 
que desde 2015 passou a fazer parte da Base Nacional Curricular Comum $(\mathrm{BNCC})^{4}$, e das novas tecnologias.

O produto educacional aqui apresentado é resultado de nossa pesquisa de mestrado profissional realizada com alunos do $9^{\circ}$ ano do ensino fundamental de uma escola pública de Juiz de Fora. Os alunos participaram voluntariamente do trabalho e puderam colaborar através das interações com melhorias na criação de tarefas para serem utilizadas por meio de chat, bem como contribuíram para a construção do tutorial para professores de matemática que desejam utilizar as tarefas nas aulas de educação financeira via essa ferramenta tecnológica.

O desenvolvimento de aulas chats de educação financeira é um desafio, mas a pesquisa que deu origem ao produto educacional revelou que é um desafio possível. Algumas dificuldades foram enfrentadas no decorrer do caminho, dentre elas a exigência de uma grande carga horária extra por parte do professor, já que ele tem que estar em cada grupo de sua turma mediando às interações. $E$ para que as interações sejam acompanhadas são necessários diversos dias e horários distintos dos grupos para a realização das tarefas. Esse ponto também foi pesado para os alunos, pois muitos deles tinham outros compromissos extraescolares e enfrentaram dificuldades no momento de conciliarem um horário em comum para as aulas no Hangouts.

Outro fator que deve ser levado em conta é a dependência da internet para a prática das aulas online, visto que alguns integrantes dos grupos podem ficar desconectados por alguns instantes. Isso aconteceu em nossa pesquisa, mas não comprometeu de forma significativa pelo fato da interrupção da internet ter ocorrido por poucos minutos.

Nossa expectativa é que essas tarefas disponibilizadas juntamente com o tutorial possam ser úteis para os professores de matemática interessados nesse tipo de abordagem e sirva de inspiração para desenvolvimento de aulas de educação financeira com o uso dessa ferramenta tecnológica.

\footnotetext{
${ }^{4}$ Referência nacional para formulação dos currículos das redes municipais, estaduais e federais de ensino no Brasil.
} 


\section{Referências}

BAUMAN, Zygmunt. Vida para Consumo: a transformação das pessoas em mercadoria. Rio de Janeiro: Editora Zahar, 2008.

GONZÁLEZ, BEATRIZ \& LEÓN, ANIBAL. Interacción Verbal Y Socialización Cognitiva e Nel Aula. Acción Pedagógica, № 18, Enero - Diciembre, 2009, pp. 30 - 41

KISTEMANN JR, M. A. Sobre a produção de significados e a tomada de decisão de indivíduos-consumidores. Rio Claro: UNESP, 2011. 540 f. Tese (Doutorado em Educação Matemática) - Programa de Pós-Graduação em Educação Matemática, Universidade Estadual Paulista, Rio Claro, 2011.

LINS, R.C. Por que discutir teoria do conhecimento é relevante para a Educação Matemática. In: Bicudo, M. A. V. (org.). Pesquisa em Educação Matemática: concepções e perspectivas. São Paulo: Editora da UNESP, 1999. P.7594.

SILVA, A.M. Sobre a dinâmica da produção de significados para a Matemática. Tese (Doutorado em Educação Matemática). Rio Claro/SP: UNESP, 2003.

SILVA, L. J. Educação matemática e ambientes virtuais: uma análise das interações ocorridas em um chat educacional. 2013. 299 f. Tese (doutorado) - Universidade Estadual Paulista, Faculdade de Ciências, 2013. 